\title{
Historia de la sangre de Alfredo Castro: entre lo real y lo perverso
}

\section{Resumen}

El objetivo de este ensayo es analizar la obra dramática Historia de la sangre (1991) de Alfredo Castro, en el marco teórico de la aproximación lacaniana al concepto de perversión. Según la crítica, esta obra pretende representar, en el nivel escénico, un exabrupto de lo real - entendido como lo traumático, lo no mediatizado y lo irrepresentable- como una forma de resistencia artística. Sin embargo, propongo que Historia de la sangre no logra representar lo real en escena; por el contrario, a través de un discurso perverso, nos muestra significaciones fallidas de ella (fantasmas, materialidades y significantes rotos). En suma, sostengo que el trabajo de Castro revela/ acusa las estéticas, éticas y políticas de la memoria/olvido instauradas en el Chile de post-dictadura.

Palabras claves

Dramaturgias chilenas, perversión, lo real, post-dictadura-aspectos culturales

\begin{abstract}
The objective of this essay is to analyze the play Historia de la sangre (1991) by Alfredo Castro taking a Lacanian approach to the concept of perversion. According to many scholars, this dramatic play attempts to stage an incursion of the Real- understood as the traumatic, the unmediated and unrepresentable truth repressed by Chilean dictatorship (1973-88)- as a form of artistic resistance. Nevertheless, I propose that Historia de la sangre is unsuccessful in its staging of the Real; on the contrary, by enunciating a perverse discourse, it presents failed signifiers that endure the repression (ghosts, broken materialities and meanings). In summary, I maintain that Castro's work allegorizes the aesthetics, ethics, and politics of both memory and forgetting in post- dictatorial Chile.
\end{abstract}

Keywords

Chilean Playwrights, Perversion, the Real, Cultural Aspects of the Post-Dictatorship

"La realidad está ahí sufriendo, está aguantada, a la espera" —Jaques Lacan: Seminario XI

"Padre ¿acaso no vez que ardo?"

—Sigmund Freud: La interpretación de los sueños. 
Resulta difícil abordar analíticamente acciones culturales que surgen de la resistencia a un contexto dictatorial represivo. En primer lugar, porque como parte de una generación que nació en democracia y que, por lo tanto, no puede acceder a estas manifestaciones desde la memoria de su vivencia, tan solo nos quedan los registros y la imaginación de sus vacíos. En segundo lugar, porque la retrospección analítica tiende a forzar la intención original de dichas manifestaciones culturales, que buscaban la vivencia de la acción artística desde la autenticidad corporeizada del arte-situación. Sólo nos queda entonces, la retrospección de sus ecos y mitificaciones posteriores.

En el arte como forma de resistencia, en el caso del Chile dictatorial de los 80 al menos, se evidencia la búsqueda de una suerte de autenticidad vivencial en el acto performativo que se expresa en la inmediatez espacio-temporal de la acción de arte. Esta materialización corporal evidencia el intento imposible del arte vanguardista de transformar la representación en ruido fenomenológico, cosificar la ficción artística en lo real traumático, deseo que busca cumplirse en una doble autenticidad: la intervención inmediata de un espacio para resignificarlo de forma inesperada (lo que se ejemplifica en las intervenciones urbanas del CADA) y la transformación corporal en tanto soporte artístico y pictórico maleable a cortes o auto-mutilaciones (las performances de Raúl Zurita, Carlos Leppe, Francisco Copello, entre muchos otros). Estas acciones, son expresiones artísticas que, en un contexto opresivo en donde se tortura sistemáticamente al cuerpo, surgen consecuentemente desde la autenticidad de la lucha. Prima, entonces, la concepción de que la única posibilidad para el arte de asumir la realidad represiva de una contingencia política, es transformarse ella misma en contingente, asumir lo cambiante en las vicisitudes corporales de la performance. La dificultad analítica se expresa, en definitiva, en la imposibilidad de acercarnos a estas acciones artísticas desde la "verdad" corporal que dichas manifestaciones pretendían ya que el arte de resistencia expresa una filosofía artística que, ante una ley autoritaria marcada y neurótica en términos psicoanalíticos, propone un 
exabrupto de lo real que ahora solo podemos abordar en el terreno de lo simbólico.

Pese a lo anterior, el remontaje de una serie de obras de teatro que se estrenaron originalmente durante la dictadura o poco después de ella, gracias al marco del festival Santiago a Mil 2010, nos permitió como generación apreciar en un nuevo contexto esta necesidad de corporalidad y autenticidad en la obra artística de resistencia. Entre estos reestrenos, a mi parecer, el más destacado en cuanto a la expresión de un arte cosificado, es la obra dramática Historia de la sangre dirigida por Alfredo Castro. Historia de la sangre - segundo montaje de la llamada "Trilogía Testimonial” del Teatro La Memoria— si bien no se estrenó durante la dictadura sino en un periodo de transición política (principios de los 90) es heredera directa de esta corporalidad del arte de resistencia a un nivel no urbano, pero sí propiamente escénico.

El teatro La Memoria (1986), con Alfredo Castro como principal director artístico, es una de las principales compañías experimentales estandartes de lo que fue un cambio con respecto a la función del texto dramático y la puesta en escena a fines de los años 80; tendencia que compartió junto a otros directores/dramaturgos coetáneos pero en una línea estética distinta como Ramón Griffero y Andrés Pérez (Lagos 104). La trilogía testimonial, compuesta por los montajes La manzana de Adán (1990), Historia de la sangre (1991) y Los días tuertos (1993), tal como señala su nombre, posicionó a la dramaturgia y dirección de Castro como un lenguaje nuevo que se configura desde la diferencia y la pretensión de una autenticidad dramática presente en el uso del testimonio. En ella se nos muestra personajes asociados con una marginalidad ya no solamente económica sino también política, normativa y ética. Así, los huérfanos monólogos de travestis prostibularios (La manzana de Adán), filicidas (Historia de la sangre) y cuidadores de tumbas (Los días tuertos) entre muchos otros, son el producto de una serie de recopilaciones orales e investigaciones psiquiátricas.

Por esta razón, las tres obras mencionadas fueron consideradas por la recepción crítica de la época como una forma de resistencia artística en relación a 
un poder hegemónico y político heredado de la dictadura que, desde la contingencia teatral, corporal y testimonial, muestran un lenguaje otro y olvidado. Con Historia de la sangre esta aproximación fue particularmente fuerte, sobre todo si consideramos que es la obra que más indaga en el lenguaje y los silencios de los testimonios de los cuerpos marginales que presenta. Los apelativos que pretenden caracterizar a este montaje, como una poética que muestra el otro lado de la norma política y artística son variados: "Poética de la marginalidad" (Lagos 104), "los no-heroicos, los no-próceres, los no padres de la patria" (110), "las historias no representadas o [...] no representables" (Röttger 116), entre muchos otros ejemplos. Se deduce entonces, que estos son nombres que, desde una negatividad analítica, consideran que la resistencia y autenticidad estética presente en este montaje en particular se da en mostrar no las consecuencias y desvíos de una cierta ley o poder autoritario, sino el otro lado no considerado ni mediatizado por dicha ley.

Ahora bien, Historia de la sangre al situarse en un contexto de transición, también evidencia una transformación respecto de la vanguardia artística anterior, situándose en un estado intermedio entre el afán reivindicatorio del arte de los 80 versus el pesimismo postmoderno que surge ya en la consolidación definitiva y más tardía del neoliberalismo en Chile. Como demostraré, si bien esta obra por una parte hereda la exaltación corporal del arte de resistencia, a su vez, revela un cambio que, propongo, se refleja en la incorporación del discurso perverso en la conformación de sus personajes. Dicha idea implica entender este montaje ya no solo como una puesta en escena que desde la supuesta resistencia artística nos muestra el otro lado de una versión o norma, sino justamente como una obra que hace de esa norma y versión existente una per-versión escénica. La interpretación que propondré aquí es entonces, contraria al de la recepción crítica ya citada. Pienso que es relevante entender que esta obra nos muestra personajes que para lograr asumir simbólicamente el trauma del asesinato intentan sin éxito instalar una norma simbólica a través de un lenguaje fallido y lleno de intersticios sintácticos. En otras palabras, la perversión en los personajes es buscar la norma, 
no problematizarla, por lo que el testimonio en el montaje, no es tanto un lenguaje "otro" ni "a-histórico" como un lenguaje que busca desesperadamente situarse en una ley simbólica, sin lograrlo completamente. Es acaso dicho discurso que los personajes planean asumir el que, planteo, refleja el proceso de transición política de Chile y el constructo simbólico que tuvo que crear para asumir el trauma dictatorial en el principio de los 90.

Escrita por Rodrigo Pérez, Francesca Lombardo y Alfredo Castro, Historia de la sangre es el resultado de un periodo de 6 meses de investigaciones en cárceles y hospitales psiquiátricos. Montada originalmente en el año 1991, esta obra es la reelaboración y reconstrucción dramática de una serie de testimonios emitidos por presos psiquiátricos que cometieron crímenes pasionales. La dramaturgia se estructura mediante la superposición fragmentada de 6 monólogos a partir de estos testimonios. Los discursos psicóticos representados entonces, muestran historias de incesto, zoofilia, abuso y marginalidad, que se materializan de diferentes maneras a nivel corporal en cada personaje. En efecto, la obra representa cuerpos sumidos en un baile solitario, limitados a sus propios discursos míticos y fundacionales, cuales fantasmas corporales de una idiosincrasia nacional fallida. Isabel la Mapuche por ejemplo, representa la indígena que llega a la capital y vende su origen en la prostitución. El Chilenito Bueno, quien asesina a su mujer e hijos, da cuenta de la esperanza frustrada de un padre patrio. La perra embalsamada llamada Laika, que habla a través de una voz en off, es el origen materno manchado. La Gran Bestia, es un personaje ligado al mundo campesino chileno que sublima el asesinato paterno al incurrir en la práctica zoofílica. La chica del Peral es la mujer atrapada en su niñez al ser violada por sus padres y el Boxeador, en cambio, es el deportista raquítico que fantasea con la violación de una niña, externalizando obsesivamente ese deseo en la figura de su hermano. Por último, Rosa la descuartizadora es una suplementera de los años 20 que satisface su intento de control celópata mediante el descuartizamiento de su marido. En consecuencia, la proxémica corporal de los personajes está limitada a sus propios 
estereotipos frustrados, por lo que hay una escasa interacción dialogal que contrasta con la exaltada interacción corporal a través de bailes y coreografías.

Por esta razón, es difícil hablar de la existencia de una trama propiamente tal, en tanto la obra no muestra una progresión dramática lineal, sino más bien circular. Los textos se repiten constantemente en la enunciación de los personajes, generalmente enfatizando el tema de la ausencia paterna. Es, por lo tanto, un lenguaje obsesivo en donde los textos parecieran perder su significado y, al mismo tiempo, exaltar más su materialidad y textura fónica. Son, paradójicamente, testimonios que a medida que se desarrollan pierden cada vez más su sentido comunicativo original, como un balbuceo lingüístico que omite el acontecimiento y crimen que la originó. Tal vez, el único monólogo que tiene un desarrollo más lineal y que a ratos entrelaza a los otros personajes, es la historia de Rosa Faúndez en donde el descuartizamiento de su marido se modula en una fragmentación sintáctica general a lo largo de la puesta en escena. Con respecto a la escenografía, el montaje ocurre en un contexto espacial que tiene como función generar una suerte de sobre-estimulación sensorial en el espectador. Todo es recargado, desde los movimientos coreográficos de los actores, hasta los colores (el naranjo esquizofrénico), los vestuarios (el plástico) y la música (atonal y enrarecida). La totalidad de estos elementos configuran a la puesta en escena como un espacio físico que exige ser ocupado y recargado. La interacción corporal entre los distintos personajes sucede simultáneamente en distintos planos y tiende a enfatizar distintas partes de los cuerpos plastificados de los actores. Por lo tanto, existe un cuidadoso trabajo coreográfico que devela la inutilidad de los cuerpos representados en tanto las acciones no poseen una funcionalidad clara ya que son etéreos, lentos y autoconscientes.

Historia de la sangre, como en el arte de resistencia, pretende en términos lacanianos un Real artístico, una materialidad escénica que busca configurarse desde el trauma. Alfredo Castro, afirma al respecto en un artículo titulado $L a$ puesta en escena como lugar del crimen, que el teatro debe "escenifica[r] aquello que el espectador jamás pensó ver o escuchar, aquello que no sucedió, lo 
imposible de nombrar [...] esa escena imposible de escenificar, por ser tan real" (92). Lo importante en este fragmento es comprender qué entiende el director como lo real en el montaje. Para Castro, lo real implica justamente el contenido de la grieta que el testimonio esconde, el acontecimiento del crimen, que es el que pretende asumir la escena. En este sentido, lo real y la utopía del arte de resistencia de encarnar ese espacio, se puede definir en términos lacanianos como lo inasimilable ni mediatizado, como aquello irrepresentable que "está más allá (...) de la insistencia de los signos" (Lacan 62) y los testimonios que fallidamente los personajes intentan sostener ${ }^{1}$ En otras palabras, Castro pretende representar la "hiancia" (Lacan 70) de esos testimonios, es decir, el lugar en donde los significantes enunciados evidencian una contradicción y traspié que revela el acontecimiento real del crimen y que, en el montaje, se busca en los intersticios y heridas sanguíneas del lenguaje fragmentado que nos muestra.

Consecuentemente con la pretensión de Castro, Francesca Lombardo, a propósito del montaje analizado, trata en un artículo publicado en el archivo web del teatro La Memoria, la capacidad de esta obra para configurar un paréntesis, un Real que, en términos de Lacan, escapa de toda forma de marco normativo o representacional: "Usar del juego teatral para pensar lo impensable, instalarnos en el colmo del desvío para interrogar la norma, interpelarla y hasta comprenderla . . . Es sobre este juego catártico de los imaginario, de la prohibición y de lo real desde donde la función teatral se desata." (Lombardo, Nota para una caída oblicua). Sin embargo, contrario a esta interpretación, planteo las siguientes preguntas: ¿Historia de la sangre nos muestra el otro lado de la norma o los

\footnotetext{
${ }^{1}$ Adjunto aquí otro fragmento del artículo de Alfredo Castro en donde, a propósito de Historia de la Sangre, da cuenta cómo se intentó representar la omisión y el acontecimiento traumático de lo real escondido en el testimonio, más que enfatizar el significante de los monólogos en sí mismos: "No fueron las historias particulares, rescatadas de estas entrevistas, las que se escenificaron en Historia de la sangre, sino el encuentro de imaginarios de esos entrevistados y el mío. No se representó la vida de esos hombres y mujeres, sino todo aquello que esas vidas tenían de irrepresentable. Fragmentación, descuartizamiento, corte, hemorragia sígnica de una nada que salpica de cuerpo en cuerpo. (Castro, 91)
} 
productos desviados y fallidos de ella? ¿Evidencia el trauma y el otro lado de la historia, como generalmente la crítica lo ha descrito, o acaso las consecuencias perversas de su consolidación simbólica post-dictatorial?

Como afirma la autora en el mismo artículo, la "per-versión”, a diferencia de la norma simbólica presente en la "versión", expone sus trizaduras toda vez que en el perverso "el yo se fractur[a], una grieta lo recorre" (Lombardo). Sin embargo, a diferencia del esquizofrénico, el perverso no habla desde la fisura o paréntesis de la norma, sino desde su torrente, desde sus consecuencias simbólicas que, como veremos, no subvierte la ley, sino mas bien la instala y desvía. Por lo tanto, no es que el perverso presente la trizadura, sino que ella se hace evidente para el espectador debido a las fallidas consecuencias simbólicas que genera. Por esta razón, los personajes en la obra buscan sus propias heridas en el trauma y el origen, sin embargo, nunca las logran encontrar: "A veces me parece que mi sangre corre a torrentes, como una fuente de sollozos, pero me palpo en vano para encontrar la herida" (Alfredo Castro et al. 13). Los cuerpos en consecuencia, evidencian una grieta fundamental y fundacional, sin embargo, no pueden formular el contenido de su vacío, solo sus efectos normativos. Historia de la sangre nos muestra, en términos de Alfredo Castro, una "hemorragia signica" (91) en la forma de sustentos simbólicos, testimonios y textos que apenas logran sostenerse por si mismos. El fantasma, siempre disimula algo primero (Lacan 68) y a medida que la obra se desarrolla nos damos cuenta que los testimonios son en realidad los efectos de un silencio original, no su origen ni su realidad.

Lo Real en este montaje entonces, al incorporar el discurso perverso, está inevitablemente en un estado de latencia, escondido y a la espera. Historia de la sangre, evidencia las consecuencias simbólicas perversas presentes en la grieta que toda instalación de una norma y ley presupone, no su paréntesis o rebeldía esquizofrénica. Como afirma Lacan, preguntar por lo Real es preguntar siempre por el trauma, por esa instancia y trizadura que siempre vuelve y que, a su vez, siempre se nos escapa (63). Por lo tanto, en los subterfugios de los enigmas discursivos, de la explotación sensorial, del amarillo exacerbado, del plástico y de 
la rarefacción sintáctica, Historia de la Sangre quiere proponer un trauma original, pero en ese deseo instala otra pregunta central durante toda la obra: ¿Cuál es el sustento traumático en el constructo simbólico que esos estereotipos fallidos nos presentan y que a duras penas intentan sostener? Para comprobar la presencia del discurso perverso en esta obra, veremos la manera en que tanto los personajes en el montaje como el sujeto perverso evidencian una relación particular entre lo real y lo simbólico. Dicha relación, se basa en la externalización del deseo mediante la subjetivación de un objeto externo en un "otro", y en una falsa pasividad ante el objeto deseado.

En la apropiación psicoanalítica del discurso perverso presente en autores como Bruce Fink y James Penney, es posible apreciar un punto en común respecto de sus causas y consecuencias, esto es, el perverso como un sujeto que falla en el proceso de simbolización de lo real. Ahora bien, lo simbólico en este caso, se puede entender como un estadio en donde entran en un juego metonímico diversos significantes que en el sujeto aligeran y revisten el trauma de lo real, ya que, como afirma Bruce Fink, la palabra es menos peligrosa que lo que designa o significa. (52) Por lo tanto, el perverso ante su encuentro con el trauma que es la evidencia en el niño de la ausencia del falo en la madre y, en consecuencia, su constatación como ser deseante, no logra esta instancia aligeradora del decir significante y posteriormente en la adultez tendrá que subvertir esta falta mediante una externalización de su propio deseo en un "otro". Este es el caso, por ejemplo, del fetichista que suplementa su deseo en algún objeto externo representante del falo maternal que le permita entrar en el terreno de lo simbólico. ${ }^{2}$

En el caso particular del sujeto perverso, el padre como constructor de la ley, no provee la articulación necesaria para la apropiación simbólica del deseo

2 Desarrollemos un poco más esta última idea. Como sucede generalmente en el triangulo edípico, el niño al constatar que su madre es un ser deseante debido a su ausencia de falo, busca suplir la falta de la madre al convertirse él en su objeto de deseo. Sin embargo, hay un punto en que el niño evidencia, debido a la coartación del padre, el carácter simbólico del deseo de la madre y, por lo tanto, logra articular normalmente la falta en el terreno de lo simbólico, aligerando el trauma. 
materno por lo que el perverso tendrá que, posteriormente, instalar sus propios limites para externalizar el objeto de deseo y poder subjetivarse en lo simbólico: "[...] perversion involves the attempt to prop up the law so that limits can be set to jouissance" (Fink 38). No es arbitrario entonces, que los personajes de Historia de la Sangre, incluso en sus movimientos corporales, se vean determinados por la gran madre que es la Perra Laika. Ella representa no sólo la madre y el origen manchado en la obra sino también el objeto de deseo por parte de los personajes, lo que se evidencia en su referencia a la sirena que articula tanto lo erótico como lo tanático: "Soy la madre, incivilizada y terrible, hermana de las sirenas, alma en pena. Impongo mi mirar que fascina, mis golpes, mis caricias bajo pena de muerte o parálisis" (Castro et al. 2).

A su vez, prácticamente todos los monólogos se articulan en torno al padre, es el caso del Chilenito Bueno quien, ante la ausencia de un padre que imponga la ley, intenta representar desesperadamente la ausencia de la estructura paterna al imponer él mismo la ley en el asesinato de su familia: "Yo no quería que mis niños tuvieran un segundo papá. Por eso les corté el cuellito" (Castro et. al. 10). El padre entonces, es la representación de una ausencia que los personajes de Historia de la Sangre llaman desesperadamente para que detrás de sus constructos simbólicos pueda ver sus traumas, la herida perdida, el hecho de que se están quemando: “¡Padre me han matado, dame fuerza! Y lo maté” (Castro et al. 5). Finalmente, el perverso pide a gritos la ley del padre para poder articular la falta de la madre y traspasar exitosamente el trauma en el terreno de lo simbólico. Si así sucediera, el perverso no tendría que suplementar la falta del deseo de la madre en la externalización, ni imponer la ley para crear un otro externo y así limitar el placer.

Ahora bien, expliquemos la definición del sujeto perverso mediante un ejemplo en la obra que evidencia claramente el patrón de externalización u objetivación perversa como es el personaje de La Gran Bestia quien subvierte el trauma en la práctica zoofílica: "Mi espíritu cuando le hacen algo pega, pega, pega fuerte, pega más fuerte que yo. Mi hermano me mató a mi por la espalda. 
Cuando me mató, yo sentí que me iba a morir. Declamé: ¡Padre me han matado, dame fuerza! Y lo maté" (Castro et al. 5). Lo primero que resalta en este fragmento, es la escisión que el sujeto crea para poder superar el trauma que es lo que Fink, citando a Freud, llama "splitting of the ego" (44). Por una parte está él mismo, quien se presenta falsamente como un individuo pasivo en el asesinato, por otra parte está su espíritu que se separa del yo y asume en el sujeto el rol del "otro". El otro, en este caso, es la externalización simbólica y fantasmática que se presenta como el agente del golpe que permite situar al "yo" como ser pasivo, al igual que el sujeto relativiza su actividad en el asesinato mediante la contradicción entre el ser matado y matar. Nuevamente, la única forma en que el sujeto perverso puede superar el trauma es mediante una externalización simbólica que se convierte en el objeto de deseo, que en el caso de La Gran Bestia, son los animales. Se evidencia, que el perverso logra posicionarse en una forma particular en su búsqueda deseante ya que se protege en una falsa pasividad sexual. En otras palabras, la víctima del perverso, ya sea una persona o un objeto, se convierte en una externalización de él mismo que se transforma en el creador del deseo mientras que el perverso se salva, falsamente, de la inherente perversión de su propio deseo. Así, mediante la externalización, el perverso al no ser el impulso del deseo, evita el miedo a ser castrado, lo que implica un acto violento por parte de éste que es simbólicamente castrar al otro. De esta manera, logra un proceso único, subjetivar lo que está en realidad fuera de él.

Justamente el asesinato en Historia de la Sangre tiene relación con lo anterior en cuanto es un intento de cosificar al otro para controlarlo, lo que se evidencia en el personaje de Rosa La Descuartizadora. Dicho personaje es el único en la obra que no surge de un registro testimonial directo, ya que fue elaborado a partir de un caso real en 1923 en donde una mujer suplementera descuartizó a su pareja por celos, repartiendo sus partes en distintos puntos de Santiago: "No lo hice tiras, lo separé para que pudiera viajar. En cada miembro cortado yo también me fui, lo acompané, y ahora él y yo estamos en paz" (Castro et al. 2). En este caso, el cortar es atenuado por el constructo simbólico de separar 
lo que hace que para Roza su marido no pierda su integridad como unidad individual lo que se evidencia en el uso del pronombre "él". La diferencia es que ahora Roza puede apropiarse de su marido, puede externalizarlo exitosamente como objeto de deseo. En efecto, la celopatía es justamente la sensación perversa en el sujeto de la no apropiación del otro, es la instancia cuando la externalización subjetiva falla: "A veces cantábamos y yo creía que lo tenía" (Castro et al. 5). Rosa activamente objetiviza a su marido mediante el acto violento de la fragmentación de su cuerpo, para así volver a una falsa pasividad en donde el objeto de deseo es definitivamente posicionado. No es arbitrario entonces que generalmente los casos de descuartizamiento sean por relaciones celópatas.

Según Lacan, el significante es esencial, es lo que posibilita el juego metonímico ante una falta y un trauma que ahora puede ser dicha, puede cruzar el terreno de lo real y acomodarse en el espacio de lo simbólico. Lo inasimilable, lo real por lo tanto, siempre es taponado por una suerte de "homeostasis subjetivante" (Lacan 63) promovida por el principio de placer pero que siempre vuelve en la forma de una hiancia o grieta inevitable e insondable. Historia de la Sangre nos muestra personajes que fallan en este proceso y que mediante la externalización perversa intentan obviar y silenciar ese trauma a través de la construcción fallida de una norma. El arte de resistencia de los 80 en cambio, busca justamente lo contrario al representar mediante la cosificación corporal (que se expresa generalmente en actos sadomasoquistas) esa grieta, ese espacio inasimilable del trauma para subvertir el estrato simbólico de la ley autoritaria y neurótica que rige en la dictadura chilena. Es por esto que el arte de resistencia no es un arte perverso, ya que no necesita serlo, el otro autoritario ya está externalizado, ya hay un padre que impone una ley brutal, lo que tiene que hacer el arte de resistencia es simplemente oponerse a esa ley, salir de sus marcos representacionales mostrando el trauma de lo real. El perverso, en cambio, ante la ausencia, tiene que crear la ley para subjetivarse y ser el receptor de sus consecuencias simbólicas. 
La resistencia y la perversión son, entonces, dos expresiones políticas divergentes en la cual Historia de la sangre es una bisagra que introduce por primera vez a la segunda como una forma de deconstrucción política y artística. La perversión oculta la sangre a través de la creación de una norma simbólica que no logra entender plenamente y que revela en su discurso las grietas que pretende ocultar. La resistencia y la escena de avanzada en cambio, corta su propio brazo para mostrarle a la ley cómo se desangra. En consecuencia, el montaje no nos muestra solamente el otro lado de la historia como pretendería el discurso de resistencia, sino personajes que, desde ese otro lado, desesperadamente buscan construir una historia para precisamente esconder la sangre ya que, como afirma el mismo texto del montaje, "Aquel que sangra, muestra que la sangre no hace trampas, jamás" (Castro, et al. 8).

El montaje analizado por lo tanto, evidencia en la incorporación del discurso perverso, el contexto histórico en el cual se sitúa, a saber, un periodo de transición política en donde los bandos se tornan más ambiguos ante la democratización del sistema neoliberal creado durante la dictadura. Por esta razón, la puesta en escena nos muestra el torrente simbólico presente en la perversión de esa norma ahora instaurada en una democracia la cual rebosa las contradicciones y muertes que pretende simbolizar. Esta obra en definitiva, se mueve en un punto intermedio entre la resistencia manifestada en la subversión corporal a fines de los $80 \mathrm{y}$ el pesimismo postmoderno que el teatro posterior al año 2000 dará cuenta, en donde ya ni la resistencia es posible pues hay un orden semántico-representacional que se superpone al corporal y que siempre subsume. La resistencia presupone la existencia de algo no dicho, omitido y no representado que luego la escena impone al espectador para relativizar el estatuto y supuesta universalidad de la ley autoritaria. Sin embargo, ante el pesimismo de que lo real traumático no es representable, la perversión pareciera ser la única forma de cuestionar una norma a través de su instauración. Historia de la sangre es, entonces, una obra profundamente política en cuanto anuncia una caída; la 
CATEDRAL TOMADA: Revista de crítica literaria latinoamericana / Journal of Latin American Literary Criticism Damián Noguera

irrupción inevitable de lo real en el débil constructo simbólico que es el Chile de los 90, país que a duras penas sabe cómo lidiar con su propio trauma original.

\section{Bibliografía}

Castro, Alfredo, et al. Historia de la sangre. Producción teatro La Memoria. Santiago, Chile: s.n. 1991.

. "La puesta en escena como lugar del crimen". Apuntes 107 (1994): 91-93.

Finck, Bruce. "Perversion" en Perversion and the social relation. Ed. Molly Anne

Rothenberg, Dennis Foster, and Slavoj Zizek. United States: Duke University

Press, 2003.

Lacan, Jacques. Seminario 11: Los cuatro conceptos fundamentales del psicoanálisis. Buenos Aires: Paidós, 2011.

Lagos, Soledad. "Hacia una poética de la marginalidad en el teatro chileno de los 90”. Apuntes 112 (1997): 104-114.

Lombardo, Francesca. Notas sobre una caída oblicua. Web. 15 dic. 1995. http://teatrolamemoria.portablehost3.net/15/12/1995/notas-para-unacaida-oblicua/

Penney, James. The World of Perversion: Psichoanalysis and the Impossible Absolute of Desire. United States: State University of New York, 2006.

Röttger, Kati. "Cuerpos destrozados: recuerdos a una nación en La hisotria de la sangre del grupo chileno Teatro La Memoria". Apuntes 112 (1997): 115127 States License.

ULIS D-Sorle This site is published by the University Library System, University of Pittsburgh as part of its D-Scribe Digital Publishing Program and is cosponsored by the University of Pittsburgh Press.
} 